\title{
Composição do leite e diagnóstico de mastite em caprinos
}

\author{
Milk composition and mastitis diagnosis in goats
}

\section{Carina Morais Correa ${ }^{1}$, Raquel Michaelsen ${ }^{2}$, Maria Edi da Rocha Ribeiro ${ }^{3}$, Andrea Troller Pinto ${ }^{2}$, Maira Balbinotti Zanela² \& Verônica Schmidt ${ }^{2}$}

\begin{abstract}
Background: Milk is one of the most used foodstuffs by humans in their diet. The quality of goat milk is already regulated by Law, which takes into consideration its physical-chemical and microbiological composition parameters. Several factors contribute for the alteration of the physical-chemical and microbiological parameters of caprine milk. These include breed, age, lactation phase and diet, among others. The health status of animals may interfere in the quality of the milk produced, both regarding food safety and milk processing and, for that reason, the identification of mastitis-causing agents is important, so that prevention and control measures can be implemented. The present study aimed at analyzing the occurrence of mastitis and the milk composition of dairy goats in a semi-intensive production system.

Materials, Methods \& Results: In a private goat farm with a flock composed of 32 female animals of breeds such as Saanen and Anglo-Nubian, raised on a semi-confined system, the diagnosis of mastitis was made through methods such as California Mastitis Test (CMT), Somatic Cells Count (SCC) and bacterial isolation. A total of 136 milk samples were analyzed, which were individualized per teat. Additionally, the study determined the volume of milk produced individually and the chemical composition of milk samples (fat, raw protein, lactose and total solids). In 37 (27.2\%) samples, subclinical mastitis caused by CNS was identified. A negative response to CMT was observed in $125(91.92 \%)$ samples. Only four samples presented a coincidence (OR=1.239) between $\mathrm{CMT}$ and bacterial isolation ( $\mathrm{P}=0.7470$ ). It was observed that the daily milk production ranged between $207.90 \mathrm{~mL}$ and $2.68 \mathrm{~L}$. Moreover, it became clear that the milk production in half of the teats with subclinical mastitis was smaller $(\mathrm{P}=0.0026)$. A tendency to a significant reduction $(\mathrm{p}<0.001)$ in the percentage of fat and total solids was verified. The lactose percentage remained stable during the four months, and that of protein showed a tendency to reduction ( $\mathrm{p}<0.001)$. A great variability in SCC was observed (23,000 to 9,999,000 cel. $\left.\mathrm{mL}^{-1}\right)$ during the sampling months. A significant concordance $(\mathrm{P}<0.001)$ was determined between a low SCC and the non-bacterial isolation in 65 samples ( $\mathrm{OR}=11.556)$.

Discussion: Mastitis is an inflammation of the mammary gland and, in the majority of cases, it is manifested in its subclinical form, having CNS as its main agent, both in Brazil and in other countries. Methods such as bacterial isolation, SCC and CMT are used for the diagnosis of mastitis. In the present study, no relation among these diagnostic methods has been found. This fact had already been reported in Brazilian literature. The herd configuration may have contributed for the occurrence of mastitis, since this disease is influenced by genetic factors and age. Moreover, its occurrence was higher in Anglo-Nubian females which, in addition to being older and consequently having undergone a higher number of lactations, presented an udder conformation with fragile ligaments and pending teats. Such conformation of the mammary glands may collaborate to the occurrence of infection. Mastitis is responsible for damages in the dairy production system, due to economical losses and reduction in the quality and volume of milk. However, the present study did not observe a variation in milk production due to bacterial contamination or an increase of SCC. A reduction in solid and fat contents did coincide with the beginning of the lactation period in Saanen goats; animals belonging to this breed tend to produce a higher volume of milk and, consequently, a smaller proportion of its components is observed. Based on the results obtained, the study concluded that the herd composition with regard to breed and lactation phase has an influence in the occurrence of subclinical mastitis, as well as in milk composition. Methods such as the CMT and SCC should be used carefully in the diagnosis of mastitis in goats.
\end{abstract}

Key-words: dairy goats, mastitis, milk yield, milk production.

Descritores: caprinos leiteiros, mastite, composição do leite, produção leiteira.

Received: Janaury $2010 \quad$ www.ufrgs.br Accepted: April 2010

${ }^{1}$ Programa de Pós-graduação em Ciências Veterinárias (PPGCV), Universidade Federal do Rio Grande do Sul (UFRGS), Av. Bento Gonçalves n. 9090, CEP 91540-000 Porto Alegre, RS, Brasil. ${ }^{2}$ Departamento de Medicina Veterinária Preventiva, Faculdade de Veterinária, UFRGS. ${ }^{3}$ Laboratório da Qualidade do Leite, Embrapa Clima Temperado, Pelotas, RS. CORRESPONDÊNCIA: V. Schmidt [veronica.schmidt@ufrgs.br - FAX: +55 (51) 3308-7305]. 


\section{INTRODUÇÃO}

O leite é um dos alimentos mais utilizados pelo homem na sua alimentação. A qualidade do leite caprino já é regulamentada pela legislação que observa parâmetros de composição físico-química e microbiológica.

Os aspectos físico-químicos do leite contribuem para a caracterização do sistema de produção no que diz respeito à alimentação correta dos animais, assim como possíveis fraudes que alterem sua composição. Já a avaliação microbiológica permite controlar a qualidade higiênica aplicada na propriedade leiteira e é de grande importância, pois microorganismos patogênicos podem ser transmitidos ao homem, comprometendo sua saúde, assim como prejudicar ou impedir o beneficiamento do leite.

A sanidade da glândula mamária pode interferir na qualidade do leite produzido tanto do ponto de vista da segurança alimentar quanto no beneficiamento do leite. Neste sentido, a identificação dos agentes de mastite bem como dos fatores predisponentes e determinantes desta enfermidade se fazem necessários para seu controle em animais de produção leiteira.

O presente estudo teve por objetivo analisar a ocorrência de mastite e a composição do leite em cabras leiteiras em sistema semi-intensivo de produção.

\section{MATERIAIS E MÉTODOS}

Realizou-se um estudo observacional longitudinal e amostragem por conveniência [31] em uma propriedade privada no município de Gravataí, RS. O capril possuía 32 animais em lactação, sendo o rebanho composto igualmente por animais das raças Saanen e Anglonubiana. Os animais eram criados em sistema semi-intensivo de produção, não realizando o controle qualitativo nem quantitativo do alimento fornecido. Os animais recebiam como base da alimentação pastagem de Capim Tifton (Cynodon nlemfuensis) e complementação com concentrado. A ordenha mecânica era realizada uma vez ao dia.

Para o diagnóstico de mastite, em visitas mensais no período de junho a setembro de 2008, realizou-se o California Mastitis Test (CMT)[29] e o exame bacteriológico de amostras do leite individualizadas por teta [33] em todos os animais em lactação no momento da coleta, totalizando 136 amostras. Estas foram semeadas em ágar acrescido de sangue de carneiro $(5 \%)$, incubadas à $37^{\circ} \mathrm{C}$ de 24 a 48 horas, sendo, a seguir, contadas as unidades formadoras de colônia [6] e realizada a identificação bacteriana [16]. As fêmeas foram esgotadas manualmente e a produção, individualizada por teta, foi pesada em balança de precisão. Após homogeneização, cerca de 50 $\mathrm{mL}$ de leite coletados em frasco contendo bromopol ${ }^{1}{ }^{1}$ (pastilhas contendo 20\% de 2-bromo-2-nitropropano1, 3-diol) foram encaminhadas ao Laboratório de Qualidade do Leite da EMBRAPA Clima Temperado para determinação da composição (gordura, proteína bruta, lactose e sólidos totais) por infravermelho e Contagem de Células Somáticas por citometria de fluxo.

Os valores de CCS foram convertidos em logaritmo de base 10. Os dados de produção de leite quanto ao status sanitário foram comparados pelo teste de Mann-Whitney; os dados de composição do leite, quanto ao mês de coleta, pelo teste de ANOVA e KruskalWallis, com um erro de $0,5 \%$. A análise de concordância (Odds Ratio) entre os resultados de isolamento bacteriano e CMT foram realizados pelo Teste Exato de Fischer. Utilizou-se o Programa estatístico GraphPad Prism.

\section{RESULTADOS}

Verificou-se que, no primeiro mês de amostragem, o rebanho em lactação era constituído por 8 cabras da raça Anglonubiana na $3^{\mathrm{a}}$ fase de lactação (entre 8 e 12 semanas), considerada como pico de produção [1]. Já no mês de julho, além das cabras Anglonubianas, uma cabra Saanen foi integrada ao rebanho em lactação e, em agosto, teve início o período de parição das cabras Saanen. Nos meses de agosto e setembro, o rebanho em lactação era constituído por 8 cabras Anglonubianas, já na $4^{a}$ fase de lactação (decréscimo de produção), 17 cabras Saanen e duas cabras cruza Anglonubaina e Saanen ( $1 / 2$ sangue), nas $2^{\mathrm{a}}$ e $3^{\mathrm{a}}$ fases de lactação (aumento e pico de produção), respectivamente.

Não se verificou a ocorrência de mastite clínica no período. Por outro lado, em 37 (27,2\%) amostras verificou-se isolamento bacteriano compatível com mastite subclínica, identificando-se Staphylococcus coagulase-negativo em todas as amostras. Determinou-se que a ocorrência de mastite subclínica nos meses de junho e julho foi superior aos meses agosto e setembro (Figura 1).

Observou-se resposta negativa ao CMT em 125 (91,92\%) amostras. Em quatro amostras, observou-se reação 2 ou 3 e em 9, reação suspeita no CMT. Em apenas quatro amostras houve coincidência $(\mathrm{OR}=1,239)$ entre o CMT e o isolamento bacteriano $(\mathrm{P}=0,7470)$. 


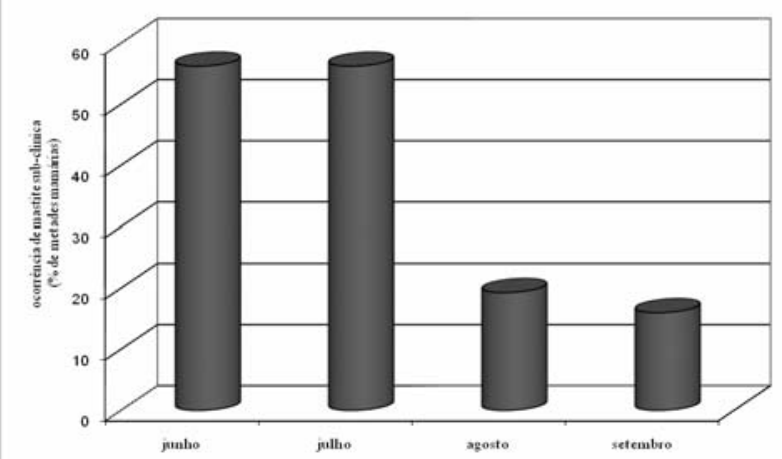

Figura 1. Percentual de metades mamárias de cabras Saanen e Anglonubiana com mastite subclínica pertencentes a um capril situado no município de Gravataí, RS, segundo o mês de amostragem durante o ano de 2008.

Observou-se que a produção diária de leite variou de $207,90 \mathrm{~mL}$ a 2,68 L, sendo o valor mediano do rebanho cerca de 1,5 L/dia. Determinou-se que a produção de leite em metades mamárias com isolamento bacteriano foi significativamente menor $(\mathrm{P}=0,0026)$ do que naquelas sadias, observando-se valores medianos de 0,48 e $0,65 \mathrm{~L}$, respectivamente.

A composição do leite caprino no período de junho a setembro é apresentada na Figura 2. Verificou-se redução significativa $(\mathrm{p}<0,001)$ nos percentuais de gordura e sólidos totais nos meses de agosto e setembro comparados aos meses de junho e julho. O percentual de lactose manteve-se estável ao longo dos quatro meses e a proteína apresentou baixa redução, porém significativa $(\mathrm{p}<0,001)$ apenas no mês de setembro.

Embora se tenha observado grande variabilidade na CCS (23.000 a 9.999 .000 células. $\left.\mathrm{mL}^{-1}\right)$, esta não foi significativa ao longo dos meses de amostragem (Figura 3).

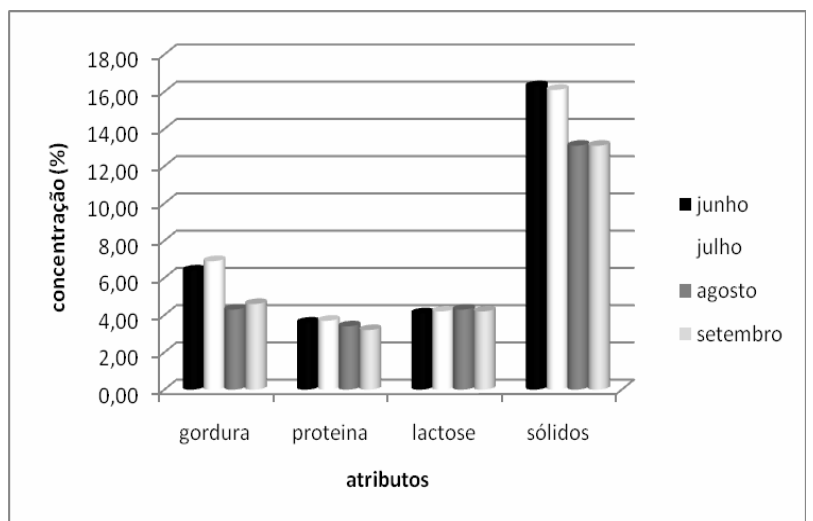

Figura 2. Percentual mediano dos componentes do leite de cabras Saanen e Anglonubiana pertencentes a um capril situado no município de Gravataí, RS, segundo o mês de amostragem durante o ano de 2008.

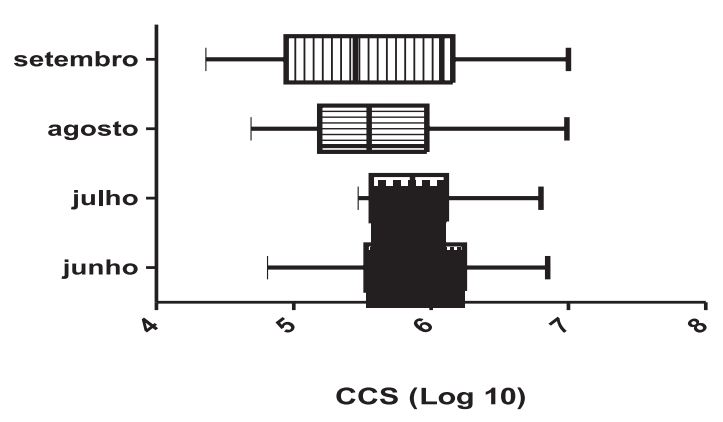

Figura 3. Box plot da Contagem média de Células Somáticas (CCS) em leite de cabras Saanen e Anglonubiana pertencentes a um capril situado no município de Gravataí, RS, segundo o mês de amostragem durante o ano de 2008.

Determinou-se que $10(7,25 \%)$ amostras apresentaram contagens superiores a $2,5 \times 10^{6} \mathrm{cél}^{\mathrm{m}} \mathrm{mL}^{-1}$, sendo que uma fêmea apresentou as duas metades mamárias com contagens superiores a este valor em duas amostragens consecutivas, entre estas, uma fêmea encontrava-se em primeira lactação e com suspeita de estar infectada pelo vírus da artrite encefalite caprina (CAE). Fêmeas soropositivas para CAE apresentam aumento significativo na CCS [32]. Fêmeas que apresentaram uma das glândulas com alta CCS não tiveram diferença significativa no volume de leite produzido, quando comparadas àquelas com glândula saudável e a com alta CCS $(\mathrm{P}=0,5625)$.

Em apenas duas metades mamárias observou-se coincidência entre o isolamento bacteriano e a CCS superior a 2,5 milhões de células. Em seis fêmeas, observaram-se contagens de CCS menores que $5 \times 10^{3}$ cél. $\mathrm{mL}^{-1}$, em amostragens consecutivas. Considerando-se este valor como úbere saudável no diagnóstico de mastite [3], determinou-se concordância significativa $(\mathrm{P}<0,001)$ entre baixa $C C S$ e o não isolamento bacteriano em 65 amostras $(\mathrm{OR}=11,556)$.

\section{DISCUSSÃO}

A mastite é uma inflamação que ocorre na glândula mamária e pode apresentar-se na forma clínica ou subclínica, sendo causada, na maioria dos casos, por microorganismos [10]. Na forma clínica, pouco frequente em caprinos [8], os animais apresentam sinais como endurecimento e dor na glândula, edema, aumento da temperatura, resquícios de pus, grumos ou outras alterações no leite [10].

A mastite subclínica tem no Staphylococcus coagulase-negativo ( $\mathrm{SCN}$ ) o principal agente, tanto no Brasil [21,22,30] como em outros países $[6,8,12,13,17,26,28,35]$. O predomínio de SCN po- 
deria ser justificado pela presença destas bactérias na microbiota da pele e conjuntiva dos animais, particularmente no úbere de fêmeas leiteiras [20].

Para o diagnóstico da mastite, podem-se utilizar métodos como o CMT, exame clínico, análises microbiológicas e CCS. O CMT é um teste muito prático, pois pode ser realizado no capril durante a ordenha e tem como princípio a estimativa da contagem de células somáticas no leite [25]. Entretanto, não foi observada relação entre este método diagnóstico e os demais. Baixa relação entre o CMT e o isolamento bacteriano já anteriormente observado em cabras [30].

A redução da produção leiteira em fêmeas com mastite ocorre como consequência da deterioração das células secretoras e consequente acúmulo de leite, oclusão dos canais secretores e diminuição da síntese de leite [14]. Este quadro tem sido descrito também em bovinos [11] e ovinos [2].

A ocorrência de maior número de casos de mastite no início do período de observações pode ser decorrente da configuração do rebanho, uma vez que esta enfermidade sofre influência ligada a fatores genéticos e idade [4] e a ocorrência foi maior em fêmeas Anglonubianas que, além de apresentarem mais idade e consequente maior número de lactações, apresentam conformação de úbere com fragilidade de ligamentos e tetas pendentes. Esta conformação de aparelho mamário pode colaborar para a ocorrência de infecção [27].

A diminuição dos teores de sólidos e gordura coincidiu com o início de lactação de cabras Saanen e animais desta raça tendem a produzir maior volume de leite e, consequentemente, menor proporção de seus componentes.

A mastite provoca transtornos na secreção láctea e quanto mais grave, mais a composição do leite se aproxima à composição sanguínea [14], caracterizando-se por diminuição na lactose, gordura e caseína [14,19] e aumento das proteínas do soro [14].

O teor de gordura do leite pode variar muito segundo a época do ano, região geográfica e manejo, mas, sem dúvida, o fator que mais contribui para esta variação foi a dieta do rebanho. Em bovinos, rações pobres em fibras podem resultar em redução de 50\% do conteúdo de matéria gorda no leite [34].

A composição físico-química do leite de cabra, segundo a legislação brasileira [5], deve apresentar teor de gordura original da raça explorada no caso de leite integral, no máximo $0,5 \%$ no leite desnatado e de 0,6 a 2,9\% no leite semi desnatado; a acidez deve ser de 0,13 a $0,18^{\circ} \mathrm{D}$; mínimo de $8,2 \%$ de sólidos não gordurosos; densidade de 1,0280 a $1,0340 \mathrm{~g} / \mathrm{L}$ a $15^{\circ} \mathrm{C}$; mínimo de $2,8 \%$ de proteína; mínimo de $4,3 \%$ de lactose e $0,70 \%$ de cinzas.

No presente estudo, observou-se discordância com a legislação quanto ao teor de lactose em 71 $(52,21 \%)$ amostras. Concentração média de lactose abaixo do estabelecido na legislação já foi anteriormente observada [7,24] em leite caprino no Brasil.

A contagem de células somáticas, apesar de ainda não possuir um padrão para caprinos, representa uma forma de detecção de mamite e contagens a partir de $10^{6}$ células $/ \mathrm{mL}$ tem sido usada como base para leite com mamite [23]. No presente estudo, não foi observada concordância entre isolamento bacteriano e altas contagens de CCS. Estudos têm apontado para a necessidade de se estabelecer um limite de CCS para a espécie caprina, inclusive como estímulo ao pagamento do leite por qualidade [7].

Células somáticas são células da corrente sanguínea, como leucócitos, e também provenientes da descamação natural do epitélio glandular secretor [18]. $\mathrm{O}$ leite de cabra possui, naturalmente, maior número de células somáticas em relação ao leite de vaca, resultante da maior descamação do epitélio da glândula [10].

A composição do rebanho também pode ter influenciado nos valores de CCS e nas variações dos componentes do leite ao longo do tempo. Uma vez que a qualidade do leite, no que diz respeito à composição, é afetada por uma série de fatores, tais como manejo nutricional, manejo sanitário do rebanho e raça [19]. Além disso, contagens elevadas de CCS são relatadas em fêmeas com CAE (artrite-encefalite caprina) [4,32]. No rebanho em estudo, embora as fêmeas não tenham apresentado resposta imune à enfermidade, as fêmeas Saanen em primeira lactação foram, equivocadamente, alimentadas enquanto cabritas com leite proveniente de rebanho sorologicamente reagentes para CAE. Este fato associado ao período de declínio de lactação nas fêmeas Anglonubianas poderia contribuir para o aumento da CCS no rebanho, especialmente nos meses de agosto e setembro.

\section{CONCLUSÃO}

A composição do rebanho quanto à raça e fase de lactação reflete na ocorrência de mastite subclínica assim como na constituição do leite. Métodos como CMT e CCS devem ser utilizados com cautela no diagnóstico de mastite em caprinos. 


\section{REFERÊNCIAS}

1 Agraz-Garcia A. 1981. Caprinotecnia. v.1. Guadalajara: Editora Universidad de Guadalajara, 840p.

2 Albenzio M., Taibi L., Muscio A. \& Sevi A. 2002. Prevalence and etiology of subclinical mastitis in intensively managed flocks and related changes in the

yield and quality of ewe milk. Small Ruminant Research., 43(3): 219-226.

3 Bianchi L., Bolla A., Budell E., Caroli A., Casoli C., Pauselli M. \& Duranti E. 2004. Effect of uder health status and lactation phase on the characteristics of Sardinian ewe milk. Journal of Dairy Science. 87(8): 2401-2408.

4 Boscos C., Stefanakis A., Alexopoulos C. \& Samartzi F. 1996. Prevalence of subclinical mastitis and influence of breed, parity, stage of lactation and mammary bacteriological status on Coulter Counter Counts and California Mastitis Test in the milk of Saanen and autochthonous Greek goats. Small Ruminant Research. 21(2): 139-147.

5 Brasil. 2000. Ministério da Agricultura, Pecuária e do Abastecimento. Instrução Normativa No 37, de 31 de outubro de 2000. Regulamento Técnico de Identidade e Qualidade de Leite de Cabra. Disponível em: http://extranet.agricultura.gov.br/ sislegis-consulta/servlet/VisualizarAnexo?id=1691. Acessado em: 03/2009.

6 Contreras A.J., Corrales A., Sánchez A. \& Sierra D. 1997. Persisitence of caprine intramammary pathogens throughout lactation. Journal of Dairy Science. 80(11): 2815-2819.

7 Costa M.G., Cordeiro A.G.P.C. \& Cordeiro P.R.C. 2009. Análise dos componentes do leite de cabra de rebanhos do Rio Grande do Sul. In: Anais da 46 Reunião Anual da Sociedade Brasileira de Zootecnia (Maringá/PR). pp.1-3.

8 Cremoux R. \& Menard J.L. 1996. Influence des infections mammaires sur la quantité de lait et les taux. Réussir La Chèvre. 213: 32-34.

9 East N.E., Birnie E.F. \& Farver T.B. 1987. Risk factors associated with mastitis in dairy goats. Journal of the American Veterinary Medical Association. 48(5): 776-779.

10 Gyles C.S., Prescott J.F, Songer J.G. \& Thoen C.O. 2004. Pathogenesis of bacterial infections in animals. Iowa: Blackwell, $456 \mathrm{p}$.

11 Halasa T., Nielen M., Roos A.P.W., Van Hoorne R., Jong G., Lam T.J.G.M., Van Werven T. \& Hogeveen H. 2009. Production loss due to new subclinical mastitis in Dutch dairy cows estimated with a test-day model. Journal of Dairy Science. 92(2): 599-606.

12 Hunter A.C. 1984. Microflora and somatic cell content of goat milk. Veterinary Record. 114(13): 318-320.

13 Lerondelle C. \& Poutrel B. 1984. Characteristics of non-clinical mammary infections of goat. Annales de Recherches Vétérinaires. 15(1): 105-112.

14 Luquet F.M. 1991. Leche y Productos Lacteos. v.1. Zaragoza: Acribia, 390 p.

15 Kitchen B.J. 1981. Review of the progress of dairy science: Bovine mastitis: milk compositional changes and related diagnostic tests. Journal of Dairy Research. 48(1): 167-188.

16 Mac Faddin J.F. 1977. Biochemical tests for identification of medical bacteria. Baltimore: Williams Wilking, 912 p.

17 Maisi P. \& Riipinen I. 1991. Pathogenicity of different species of Staphylococci in caprine udder. British Veterinary Journal. 147(2): 126-132.

18 Marth E.H. \& Steele J.L. 2001. Applied dairy microbiology. New York: Marcel Dekkar, 744p.

19 Medeiros L.P. 1994. Caprinos: princípios básicos para sua exploração. Brasília: EMBRAPA, 177p.

20 Moroni P., Pisoni G., Antonini M., Rufo G., Varisco G. \& Boettcher P. 2005. Subclinical mastitis and antimicrobial suscetibility of Staphylococcus caprae and Staphylococcus epidermidis isolated from two Italian goat herds. Journal of Dairy Science. 88(5): 1694-1704.

21 Mota R.A., Castro F.J.C., Silva L.B.G. \& Oliveira A.A.F. 2000. Etiologia e sensibilidade antimicrobiana in vitro das bactérias isoladas do leite de cabras com mastite procedentes da região metropolitana do Recife, Pernambuco, Brasil. A Hora Veterinária. 19(114):26-29.

22 Muricy R.F. 2003. Ocorrência de mamite subclínica em caprinos e qualidade higiênico-sanitária do leite produzidos em propriedades associadas à cooperativa Languiru, Teutônia - RS. 83f. Porto Alegre, RS. Dissertação (Mestrado em Ciências veterinárias) - Programa de Pós-graduação em Ciências Veterinárias, Universidade Federal do Rio Grande do Sul.

23 Paes P.R.O., Lopes S.T.A., Lopes R.S., Kohayagawa A., Takahira R.K. \& Langoni H. 2003. Efeitos da administração de vitamina E na infecção mamária e na contagem de células somáticas de cabras primíparas desafiadas experimentalmente com Staphylococcus aureus. Arquivo Brasileiro de Medicina Veterinária e Zootecnia. 55(1): 15-20. 
24 Pereira R.A.G., Queiroga R.C.R.E., VIanna R.P.T. \& Oliveira M.E.G. 2005. Qualidade química e física do leite de cabra distribuído no Programa Social "Pacto Novo Cariri” no Estado da Paraíba. Revista do Instituto Adolfo Lutz. 64(2): $205-211$.

25 Poutrel B. \& Lerondelle C. 1982. Cell content of goat milk: California mastitis test, coulter counter, and fossomatic for predicting half infection. Journal of Dairy Science. 66(12): 2575-2579.

26 Poutrel B., De Cremoux R., Ducelliez M. \& Verneau D. 1997. Control of intramammary infections in goats: Impact on somatic cell counts. Journal of Animal Science. 75(2): 566-570.

27 Ribeiro S.D.A.R. 1997. Caprinocultura: criação racional de caprinos. Nobel, São Paulo, 318p.

28 Ryan D.P. \& Greenwood P.L. 1990. Prevalence of udder bacteria in milk samples from four dairy goats herds. Australian Veterinary Journal. 67(10): 362-363.

29 Santos A.R., Scherer S. \& Schmidt V. 2004. Validação da Contagem de células somáticas e "California Mastitis Test” como método diagnóstico da mamite em caprinos. Revista de Ciências Agroveterinárias. 3(1): 50-55.

30 Schmidt V., Pinto A.T., Schneider R.N., Silva F.F.P. \& Mello F.A. 2009. Caracterização da mastite subclínica em caprinos produzidos em sistema orgânico no Rio Grande do Sul. Pesquisa Veterinária Brasileira. 29(9): 774-778.

31 Thrusfield M. 2004. Epidemiologia Veterinária. São Paulo: ROCA, 556p.

32 Turin L., Pisoni G., Giannino M.L., Antonini M., Rosati S., Ruffo G. \& Moroni P. 2005. Correlation between milk parameters in CAEV seropositive and negative primiparous goats during an eradication program in Italian farm. Small Ruminant Research. 57(1): 73-79.

33 Vilanova M.S. Gonçalves M., Osório M.T.M., Esteves R. \& Schmidt V. 2008. Aspectos sanitários do úbere e composição química do leite de cabras Saanen. Acta Scientiae Veterinariae. 36(3): 235-240.

34 Walstra P. \& Jeness R. 1987. Quimica y física lactologica. Zaragoza: Acribia, 423 p.

35 White E.C. \& Hinckley L.S. 1999. Prevalence of mastitis pathogens in goat milk. Small Ruminant Research. 33(2): 117-121 